\title{
Effect of chain length on catalytic activity in quaternary ammonium halides catalyzed cycloaddition of $\mathrm{CO}_{2}$ to propylene Oxide
}

\author{
Jinmin Yang ${ }^{a}$, Liping Guo ${ }^{b}$, Chen Zhuc, Hongmei Li ${ }^{d}$, Lili Huang ${ }^{e}$ \\ College of Biological, Chemical Sciences and Engineering, Jiaxing University, Jiaxing 314001, \\ China. \\ achemjmyang@163.com, ${ }^{\mathrm{b}} \mathrm{chemguolp@163.com,}{ }^{\mathrm{c}} \mathrm{chemzhuchen@163.com,}$

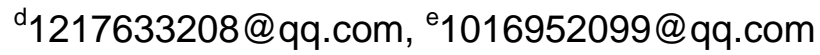

\begin{abstract}
Keywords: carbon dioxide, propylene oxide, cycloaddition, quaternary ammonium halide, Chain length influence

Abstract. A series of organic quaternary ammonium bromide with varying carbon chain length in alkyl group were investigated as the catalyst for $\mathrm{CO}_{2} / \mathrm{PO}$ cycloaddition. When the length of the single-chain in alkyl tributyl ammonium bromide increased from 2 to 16 progressively, the catalytic activity first increased and then decreased slightly. When four alkyl groups on the nitrogen atom of ammonium bromide changed from methyl, ethyl to butyl, the catalytic activity increased sharply. By changing the solvent effect of organic ammonium bromide in PO and the electrostatic interaction between cations and anions, the change of chain length might influence the concentration of "free" anions, and therefore influence the catalytic activity.
\end{abstract}

\section{Introduction}

Carbon dioxide fixation has received worldwide attention in decades, since $\mathrm{CO}_{2}$ is not only one of the greenhouse gases, but also an abundant, economical, and biorenewable resource [1, 2]. One of the most promising reactions in this area is the cycloaddition of $\mathrm{CO}_{2}$ to epoxides to prepare cyclic carbonates [3], which are widely used as polar solvents and intermediates in organic synthesis. The halide-containing organic salts, such as quaternary ammonium halides, played an important role in many catalytic systems for the cyclic carbonate synthesis [4-6]. Numbers of cocatalysts were explored and studied in details, but as the main catalyst, organic quaternary ammonium bromide had rarely been studied individually and systematically. Herein, a series of alkyl quaternary ammonium bromide were synthesized and applied to catalyze the cycloaddition of $\mathrm{CO}_{2}$ to propylene oxide (PO), and the effect of the alkyl chain length on catalytic activity would be investigated.

\section{Results and Discussion}

\section{Effect of single-chain length on the catalytic activity}

A series of alkyl tributyl ammonium bromide $\left[\mathrm{C}_{n} \mathrm{H}_{2 n+1} \mathrm{Bu}_{3} \mathrm{NBr}\right]$ with varying single carbon chain length $(\mathrm{n}=2,4,6, \ldots, 16)$ in alkyl group were investigated as the catalyst for $\mathrm{CO}_{2} / \mathrm{PO}$ cycloaddition (Figure 1). Since the main structure was almost identical, changing the length of the single-chain could not significantly affect the catalytic activity, and the yield of propylene carbonate (PC) was almost between 40 to 50 percent. But we still could observed that with chain length increasing, the 
catalytic effect were first increased and then decreased $\left(\mathrm{C}_{8} \mathrm{H}_{17} \mathrm{Bu}_{3} \mathrm{NBr}\right.$ is special, and we are still looking for the reason). The highest yield was $54.2 \%$, when $\mathrm{C}_{6} \mathrm{H}_{13} \mathrm{Bu}_{3} \mathrm{NBr}$ was as catalyst.

$\mathrm{H}_{2} \mathrm{O}$ could significantly enhance the catalytic activity of the ammonium bromide[7, 8]. Alkyl tributyl ammonium bromide could absorb moisture from the air easily, and the existence of a small amount of water in the environment might also affect the catalytic activity, thereby changing the trend of catalytic activity with chain length increasing. Therefore, in order to eliminate the influence of the small amount of water, $1 \mathrm{~mL}$ water was added to the mixture of reactant in the above reaction to equalize this influence factor. The results shown in Figure 2, the addition of $1 \mathrm{ml}$ water improved reactivity significantly. When other conditions remained unchanged and the temperature was lowered from $120{ }^{0} \mathrm{C}$ to $105{ }^{\circ} \mathrm{C}$, the PC yield of each reaction was above $60 \% . \mathrm{C}_{6} \mathrm{H}_{13} \mathrm{Bu}_{3} \mathrm{NBr}$ was still one of the highest catalytic activity materials, and the yield of PC was up to $77.9 \%$.

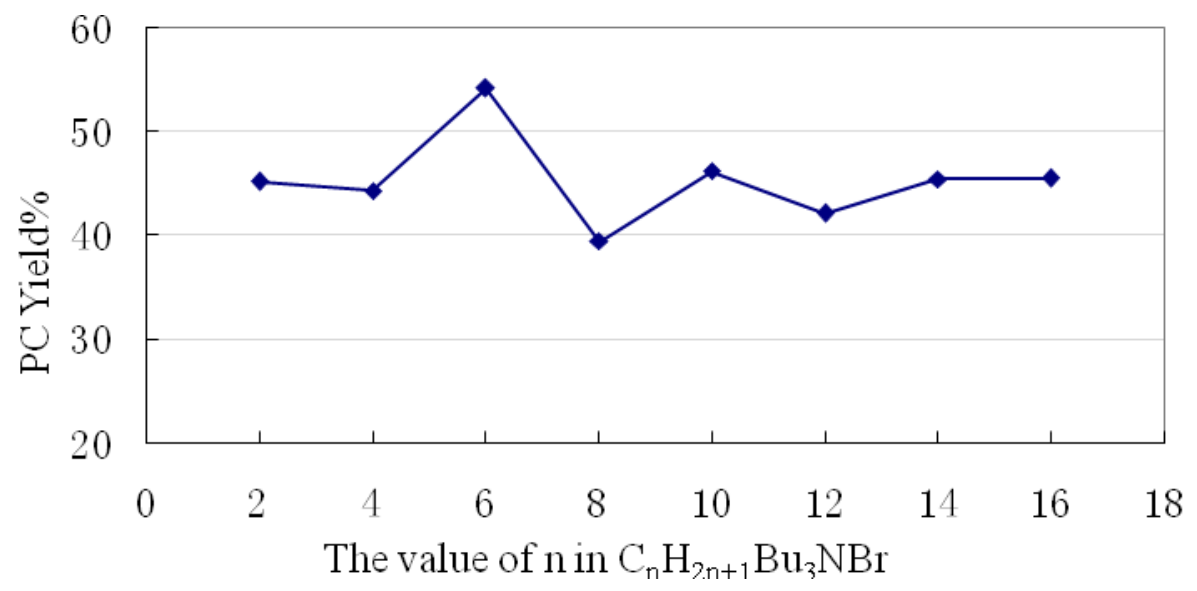

Fig.1 Effect of single-chain length on the catalytic activity. The amount of each substance: PO [0.2 mol], catalyst [1 mmol]. Reaction condition: $\mathrm{CO}_{2}$ pressure [3 $\left.\mathrm{MPa}\right], 120{ }^{0} \mathrm{C}, 2 \mathrm{~h}$. The selectivity is more than $99 \%$.

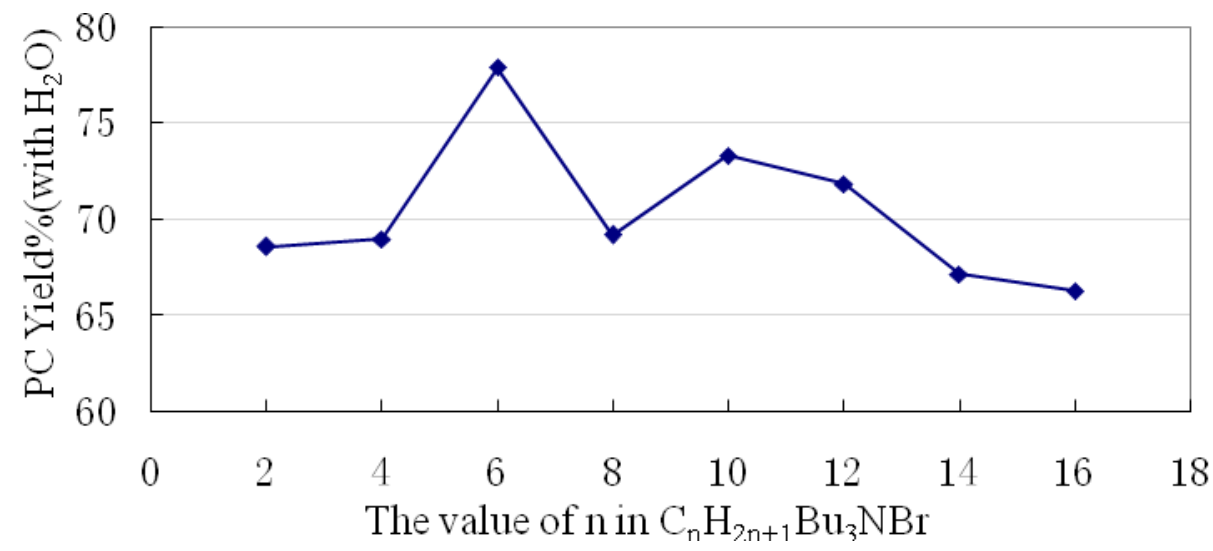

Fig.2 Effect of single-chain length on the catalytic activity (with $1 \mathrm{~mL} \mathrm{H}_{2} \mathrm{O}$ ). The amount of each substance: PO [0.2 mol], catalyst $[1 \mathrm{mmol}], \mathrm{H}_{2} \mathrm{O}[1 \mathrm{~mL}]$. Reaction condition: $\mathrm{CO}_{2}$ pressure [3 $\mathrm{MPa}], 105{ }^{\circ} \mathrm{C}, 2 \mathrm{~h}$. The selectivity is more than $97 \%$. 
The recognized mechanism for the reaction is that the halide anion opened the ring of the epoxide by means of a nucleophilic attack, which led to an oxy anion species affording the corresponding cyclic carbonate after the reaction with $\mathrm{CO}_{2}[9]$. Thus the concentration of "free" anions may determine the activity of catalyst. We presume that the change in the chain length of cations affect the electrostatic interaction between cations and anions, and therefore change the concentration of "free" anions, leading to different activity. When the carbon chain length is less than 8, with the growth of the carbon chain, cationic steric hindrance increase, so that the electrostatic interaction between cations and anions decreases, and thus the anion become more "freely", so that the catalytic activity increases gradually. When the carbon chain length is more than 8 , although the electrostatic interaction between cations and anions also decreases, we find that the solubility of catalyst in PO decreasing as the carbon chain growing, thus the concentration of "free" anions decreases finally.

\section{Effect of four-chain length on the catalytic activity}

From above research, we found that changing a single chain length could not significantly influence the activity of catalyst, and the gap of catalytic activity between the catalysts with different alkyl in single chain is not so great. So we changed four alkyl groups on the nitrogen atom of ammonium bromide $\left[\left(\mathrm{C}_{\mathrm{n}} \mathrm{H}_{2 \mathrm{n}+1}\right)_{4} \mathrm{NBr}, \mathrm{n}=1,2,4\right]$, and the effect of chain length on the catalytic activity was investigated too (Table 1). As the number of carbon increased from 1 to 4, the PC yield increased sharply. As we could see, there was only $4.8 \%$ PC generated, when the cycloaddition was catalyzed by tetramethyl ammonium bromide and carried out at $120{ }^{0} \mathrm{C}$ for 4 hours (entry 1), and while tetrabutyl ammonium bromide as a catalyst, the reaction yield rose to $55.5 \%$ (entry 3 ). $1 \mathrm{ml}$ of water was added to reaction mixture, and the catalytic activity was also studied (entry 4-6).The catalytic activity with the increase of chain length still showed the same increasing trend, and after adding water, the catalytic activity of each catalyst were greatly increased. When the cycloaddition was catalyzed by tetramethyl ammonium bromide with $1 \mathrm{~mL} \mathrm{H}_{2} \mathrm{O}$ and carried out at $105^{\circ} \mathrm{C}$ for only 1 hour, the PC yield was $8.1 \%$, and when tetrabutyl ammonium bromide as a catalyst, the reaction yield rose to $64.0 \%$.

It's worth noting that $\mathrm{Me}_{4} \mathrm{NBr}$ hardly dissolves in $\mathrm{PO}$, and $\mathrm{Bu}_{4} \mathrm{NBr}$ have good solubility. Thus we believe that in this reaction the reactants $\mathrm{PO}$ itself as an organic solvent, polarity is relatively low, and $\left(\mathrm{C}_{n} \mathrm{H}_{2 n+1}\right)_{4} \mathrm{NBr}$ as an ionic compound, therefore solvent effect is weak, so $\left(\mathrm{C}_{n} \mathrm{H}_{2 n+1}\right)_{4} \mathrm{NBr}$ either hardly dissolve or although dissolved but mostly in the form of an ion pair. With the organic substituent increased for $\mathrm{C} 1$ to $\mathrm{C} 4$ chain, the polarity of catalyst reduce, and solvent effect increase, making more "free" anions released, thus increasing the catalytic activity.

Table 1. Effect of four-chain length on the catalytic activity ${ }^{\mathrm{a}}$

\begin{tabular}{ccccccc}
\hline entry & catalyst & $\mathrm{H}_{2} \mathrm{O}[\mathrm{ml}]$ & $\begin{array}{c}\text { Temp. } \\
{\left[{ }^{0} \mathrm{C}\right]}\end{array}$ & Time $[\mathrm{h}]$ & $\begin{array}{c}\text { The amount } \\
\text { of PC }[\mathrm{g}]\end{array}$ & Yield[\%] \\
\hline 1 & $\mathrm{Me}_{4} \mathrm{NBr}$ & 0 & 120 & 4 & 0.98 & 4.796 \\
2 & $\mathrm{Et}_{4} \mathrm{NBr}$ & 0 & 120 & 4 & 5.07 & 24.810 \\
3 & $\mathrm{Bu}_{4} \mathrm{NBr}$ & 0 & 120 & 4 & 11.35 & 55.542 \\
4 & $\mathrm{Me}_{4} \mathrm{NBr}$ & 1 & 105 & 1 & 1.66 & 8.123 \\
5 & $\mathrm{Et}_{4} \mathrm{NBr}$ & 1 & 105 & 1 & 10.44 & 51.089 \\
6 & $\mathrm{Bu}_{4} \mathrm{NBr}$ & 1 & 105 & 1 & 13.08 & 64.008 \\
\hline
\end{tabular}

${ }^{\mathrm{a}}$ The amount of each substance: $\mathrm{PO}$ [0.2 mol], catalyst [1 mmol], $\mathrm{CO}_{2}$ pressure [3 MPa]. 


\section{Conclusions}

In summary, a series of alkyl quaternary ammonium bromide were synthesized and applied to catalyze the cycloaddition of $\mathrm{CO}_{2}$ and $\mathrm{PO}$, and the effect of the alkyl chain length on catalytic activity were investigated. When the length of the single-chain in alkyl tributyl ammonium bromide increased from 2 to 16 progressively, the catalytic activity first increased and then decreased slightly. When four alkyl groups on the nitrogen atom of ammonium bromide changed from methyl, ethyl to butyl, the catalytic effect increased sharply. $1 \mathrm{~mL}$ water was added into the mixture of reactant to equalize the influence to catalytic activity from a small amount of water in the environment, and it showed the same trend. We believed that, by changing the solvent effect of organic ammonium bromide in PO and the electrostatic interaction between cations and anions, the change of chain length might influence the concentration of "free" anions, and therefore influence the catalytic activity.

\section{Experimental}

All the coupling reactions were conducted in a $50 \mathrm{~mL}$ Teflon reactor equipped with a magnetic stirrer and automatic temperature control system. In a typical reaction, the reactor was charged with appropriate amount of $\mathrm{Bu}_{4} \mathrm{NBr}(0.323 \mathrm{~g}, 1 \mathrm{mmol})$, $\mathrm{PO}(11.6 \mathrm{~g}, 0.2 \mathrm{~mol})$. After the reactor was heated to $120{ }^{\circ} \mathrm{C}$, the reaction mixture was pressurized with $\mathrm{CO}_{2}$ to the desired pressure (3 $\left.\mathrm{MPa}\right)$ and stirred for $4 \mathrm{~h}$. The $\mathrm{CO}_{2}$ was charged for several times during the experiment to maintain a constant pressure $(3 \mathrm{MPa})$. Then the reactor was cooled in an ice-water bath, and the remaining $\mathrm{CO}_{2}$ was released slowly. The resulting product mixture was defied by GC-MS and ${ }^{1} \mathrm{H}$ NMR. All the products were quantitatively analyzed by gas chromatography with acetophenone as internal standard.

\section{Acknowledgements}

This work was financially supported by National Undergraduate Training Programs for Innovation (201310354022).

\section{References}

[1] M. Aresta, A. Dibenedetto, and A. Angelini, Chem. Rev., 2014, 114,1709-1742

[2] T. Sakakura, J. C. Choi and H. Yasuda, Chem. Rev., 2007, 107, 2365-2387;

[3] T. Sakakura and K. Kohno, Chem. Commun., 2009, 1312-1330

[4] C. Martín, G. Fiorani, and A.W. Kleij, ACS Catal. 2015, 5, 1353-1370

[5]Z. Zhou, C. He, J. Xiu, L.Yang, and Chunying Duan, J. Am. Chem. Soc. 2015, 137, 1506615069

[6] C. Maeda, T. Taniguchi, K. Ogawa, and T. Ema, Angew. Chem. Int. Ed., 2015, 54,134-138

[7] J. Sun, J. Y. Ren, S. J. Zhang and W. G. Cheng, Tetrahedron Lett., 2009, 50, 423-426.

[8] L. Guo, C. Wang, X. Luo, G. Cui, and H. Li, Chem.Commun., 2010, 46, 5960-5962

[9] J. W. Huang and M. Shi, J. Org. Chem., 2003, 68, 6705-6709 